\title{
Resonant Ta Doping for Enhanced Mobility in Transparent Conducting $\mathrm{SnO}_{2}$
}

Benjamin A. D. Williamson," Thomas J. Featherstone," Sanjayan S. Sathasivam, Jack E. N. Swallow, Huw Shiel, Leanne A. H. Jones, Matthew J. Smiles, Anna Regoutz, Tien-Lin Lee, Xueming Xia, Christopher Blackman, Pardeep K. Thakur, Claire J. Carmalt, Ivan P. Parkin, Tim D. Veal,* and David O. Scanlon*

Cite This: Chem. Mater. 2020, 32, 1964-1973

Read Online

ACCESS | Lill Metrics \& More | 期 Article Recommendations

Supporting Information

ABSTRACT: Transparent conducting oxides (TCOs) are ubiquitous in modern consumer electronics. $\mathrm{SnO}_{2}$ is an earth abundant, cheaper alternative to $\mathrm{In}_{2} \mathrm{O}_{3}$ as a TCO. However, its performance in terms of mobilities and conductivities lags behind that of $\operatorname{In}_{2} \mathrm{O}_{3}$. On the basis of the recent discovery of mobility and conductivity enhancements in $\mathrm{In}_{2} \mathrm{O}_{3}$ from resonant dopants, we use a combination of state-of-the-art hybrid density functional theory calculations, high resolution photoelectron spectroscopy, and semiconductor statistics modeling to understand what is the optimal dopant to maximize performance of $\mathrm{SnO}_{2}$-based TCOs. We demonstrate that $\mathrm{Ta}$ is the optimal dopant for high performance $\mathrm{SnO}_{2}$, as it is a resonant dopant which is readily incorporated into $\mathrm{SnO}_{2}$ with the Ta $5 \mathrm{~d}$ states sitting $\sim 1.4 \mathrm{eV}$ above

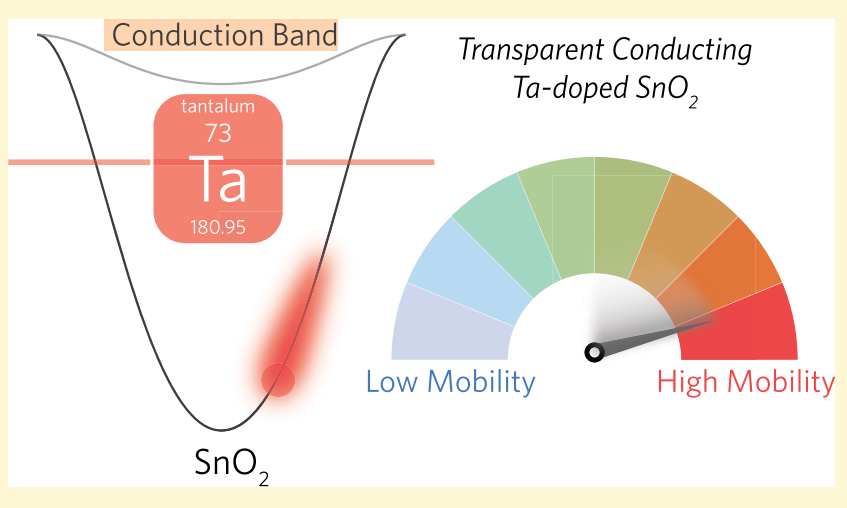
the conduction band minimum. Experimentally, the band edge electron effective mass of Ta doped $\mathrm{SnO}_{2}$ was shown to be $0.23 m_{0}$, compared to $0.29 m_{0}$ seen with conventional $\mathrm{Sb}$ doping, explaining its ability to yield higher mobilities and conductivities.

\section{INTRODUCTION}

Transparent conducting oxides (TCOs) are materials which possess the generally mutually exclusive properties of high electrical conductivity and optical transparency. These properties are achieved through degenerate doping of wide band gap semiconductors $\left(E_{\mathrm{g}}>3.1 \mathrm{eV}\right)$ giving rise to applications in a variety of crucial modern technologies such as touch screen displays, solar cells, low emissivity windows, and gas sensors. $^{1-6}$

Arguably the most successful TCO in terms of both optoelectronic properties and commercial success is $\operatorname{In}_{2} \mathrm{O}_{3}$ doped with $\mathrm{Sn}$ (ITO), which demonstrates resistivities as low as $\sim 8 \times 10^{-5} \Omega \mathrm{cm}$ and carrier concentrations exceeding $10^{21}$ $\mathrm{cm}^{-3}$ while retaining $>90 \%$ visible light transparency. ${ }^{7,8}$ ITO dominates the electronics market, however, due to the scarcity and high cost of indium, there is a pressing need to move toward alternative earth abundant TCOs particularly for applications requiring large surface areas such as photovoltaic devices and low emissivity glass coatings. ${ }^{9}$

$\mathrm{SnO}_{2}$-based TCOs are often used in such applications due to both their durability as well as the abundance and low cost of $\mathrm{Sn}$. With a suitably wide fundamental band gap of $\sim 3.6 \mathrm{eV}$, undoped $\mathrm{SnO}_{2}$ has been reported to have resistivities of $\sim 10^{-2}$ to $10^{-3} \Omega \mathrm{cm},{ }^{10}$ while $n$-type doping has achieved resistivities of $\sim 10^{-4} \Omega \mathrm{cm} .{ }^{4,11}$ Such doping is achieved by the intentional substitution of $\mathrm{Sn}$ or $\mathrm{O}$ by elements with a higher oxidation state than the element they are replacing ( $\mathrm{V}$ cations for the $\mathrm{Sn}(\mathrm{IV})$ site or VII anions for the $\mathrm{O}(\mathrm{VI})$ site). Traditional wisdom dictates that the best choice of dopant is the element positioned directly to the right of the host element in the periodic table. This represented a logical choice as they should possess both the correct oxidation state and similar ionic radii, thus minimizing lattice distortion which can lower solubility. ${ }^{4}$ Thus, $\mathrm{Sb}$ (on the Sn-site) or F (on the O site) have typically been the dopants of choice. Both F-doped $\mathrm{SnO}_{2}$ (FTO) and $\mathrm{Sb}$-doped $\mathrm{SnO}_{2}$ (ATO) thin films have displayed resistivities of $\sim 5 \times 10^{-4} \Omega \mathrm{cm}^{4,12}$ and have been successfully deposited with a wide range of techniques including pulsed laser deposition, ${ }^{13,14}$ spray pyrolysis, ${ }^{15,16}$ sol-gel, ${ }^{17,18}$ and sputtering. ${ }^{19}$

Recent reports show that FTO and ATO are inherently selflimiting as mobilities fail to surpass $\sim 35 \mathrm{~cm}^{2} \mathrm{~V}^{-1} \mathrm{~s}^{-1}$ for carrier concentrations $>3 \times 10^{20} \mathrm{~cm}^{-3} \cdot{ }^{20,21}$ The mechanism for this

Received: November 22, 2019

Revised: February 17, 2020

Published: February 18, 2020 
self-limitation was recently shown to be due to the formation of negatively charged fluorine interstitials; as the Fermi energy rises (due to doping) to $\sim 0.5 \mathrm{eV}$ above the conduction band minimum (CBM), it becomes more energetically favorable for fluorine to incorporate interstitially, thus acting as an acceptor rather than as a donor, as is the case when incorporated substitutionally. ${ }^{20}$ ATO also undergoes self-compensation, arising due to the multivalency of $\mathrm{Sb}(\mathrm{Sb}(\mathrm{III})$ and $\mathrm{Sb}(\mathrm{V})$ ), which have both been observed using both Mössbauer spectroscopy $^{22,23}$ and XPS studies. Recent DFT studies have proposed two ways in which self-compensation may occur in ATO. First, substitutional Sb defects can only act as a donor when in the $\mathrm{V}$ oxidation state and as an acceptor when in the III oxidation state. ${ }^{24,25}$ The second limitation, which was originally proposed from an X-ray absorption fine structure (EXAFS) analysis ${ }^{26,27}$ and confirmed through density functional theory calculations, was that the clustering of a substititutional $\mathrm{Sb}\left(\mathrm{Sb}_{\mathrm{Sn}}\right)$ adjacent to an oxygen vacancy $\left(\mathrm{V}_{\mathrm{O}}\right)$ leads to the formation of $\mathrm{Sb}(\mathrm{III})$ and a trapped electron in the oxygen vacancy, similar to an F-center. ${ }^{11}$

Recently, however, we have proposed and demonstrated a new doping mechanism for $\operatorname{In}_{2} \mathrm{O}_{3}$ which yields mobilities and conductivities superior to those reported for ITO. We have demonstrated that Mo-doped $\mathrm{In}_{2} \mathrm{O}_{3}$ (IMO) outperforms ITO as Mo behaves very differently from $\mathrm{Sn}$ in $\mathrm{In}_{2} \mathrm{O}_{3}{ }^{28,29}$ In ITO, $\mathrm{Sn}$ is in the (IV) oxidation state, ${ }^{30}$ and the $\mathrm{Sn} 5$ s orbitals mix with the In $5 \mathrm{~s}$ states at the bottom of the conduction band of $\mathrm{In}_{2} \mathrm{O}_{3}$. As the concentration of $\mathrm{Sn}$ is increased, the mixing at the CBM increases, increasing the effective mass of the CBM and lowering the overall mobility of the system. Mo in the IV oxidation state, on the other hand, possesses localized donor dorbitals that sit resonant in the conduction band, well separated from the CBM. This and reduced mixing of orbitals due the lack of overlap between the host s states in the CBM and the dopant $d$ states due to their different shapes ensure that minimal hybridization takes place between the dopant states and the CBM. Increasing the concentration of Mo therefore has no adverse effect on the effective mass of the CBM, allowing higher mobilities and conductivities. ${ }^{29}$ Other transition metals which have donor $\mathrm{d}$ states and incorporate in the IV oxidation state in $\mathrm{In}_{2} \mathrm{O}_{3}$ are $\mathrm{Ti}^{31}{ }^{31} \mathrm{Zr}^{32} \mathrm{Hf}^{33}$ and $\mathrm{W} .{ }^{34}$ Doping $\mathrm{In}_{2} \mathrm{O}_{3}$ with these have all demonstrated higher mobilities than ITO, indicating similar behavior to Mo.

For $\mathrm{SnO}_{2}$, the ideal donor dopant should therefore be of a similar ionic radius to either $\mathrm{Sn}$ or $\mathrm{O}$, possess donor states that sit high in the conduction band, and not hybridize with the host $\mathrm{Sn} 5 \mathrm{~s}$ states, while being in the correct oxidation state. On the basis of the successful dopants in $\operatorname{In}_{2} \mathrm{O}_{3}$, likely candidates would be transition metals which are stable in a $\mathrm{V}$ oxidation state. Three such elements exist, V, Nb, and Ta. Previous experimental studies have shown $\mathrm{V}$ to not be a shallow donor in $\mathrm{SnO}_{2}$ with $\mathrm{V}$ 3d states sitting $1.1 \mathrm{eV}$ above the valence band maximum (VBM). ${ }^{35}$ As such, $\mathrm{V}$ can be ruled out as a dopant. $\mathrm{Nb}$ doping of $\mathrm{SnO}_{2}$ has demonstrated moderate results experimentally, with high mobilities for $\mathrm{SnO}_{2}$ but suffering from low carrier concentrations, in most cases failing to reach 1 $\times 10^{20} \mathrm{~cm}^{-3} \cdot{ }^{36-38}$ Therefore, $\mathrm{Nb}$ doping warrants further investigation here from a theoretical perspective. The last of the three $\mathrm{V}$ oxidation state candidate dopants, $\mathrm{Ta}$, has shown significant promise experimentally. Thin films of Ta-doped $\mathrm{SnO}_{2}$ (TaTO) have displayed resistivities as low as $1.8 \times$ $10^{-4} \Omega \mathrm{cm}$ and have been fabricated by a wide array of deposition methods. ${ }^{39-50}$ TaTO also displays exceedingly high mobilities of up to $83 \mathrm{~cm}^{2} \mathrm{~V}^{-1} \mathrm{~s}^{-1}$ when deposited by pulsed laser deposition, ${ }^{39}$ in particular, and up to $49 \mathrm{~cm}^{2} \mathrm{~V}^{-1} \mathrm{~s}^{-1}$ when deposited by sputtering ${ }^{50}$ (at carrier concentrations of $2.7 \times$ $10^{20} \mathrm{~cm}^{-3}$ and $2.2 \times 10^{20} \mathrm{~cm}^{-3}$, respectively). This surpasses the upper mobility limits displayed by both ATO and FTO. Indeed, in cases where TaTO does not surpass the upper reported mobilities, comparative studies show that TaTO deposited by the same method as ATO displayed higher mobilities ${ }^{48}$ for the same carrier concentrations. Crucially, the origin of this improvement in performance of TaTO films over other doped $\mathrm{SnO}_{2}$ alternatives has never been elucidated.

In this study, we use hybrid density functional theory to examine the suitability of $\mathrm{Nb}$ and $\mathrm{Ta}$ as an alternative dopant for $\mathrm{SnO}_{2}$ and compare it to conventional $\mathrm{Sb}$ and $\mathrm{F}$ dopants. A consistent picture emerges of $\mathrm{Ta}$ as the ideal dopant for $\mathrm{SnO}_{2}$, possessing resonant donor states high above the CBM and minimal hybridization with CBM states. We probe the electronic structure differences between $\mathrm{Ta}$ and $\mathrm{Sb}$ dopants using semiconductor statistics modeling and hard X-ray photoelectron spectroscopy (HAXPES) of aerosol assisted chemical vapor deposition (AACVD) grown TaTO and ATO thin films. Crucially, our experimental characterization supports our computational analysis, indicating that $\mathrm{Ta}$ is the optimum dopant for high performance $\mathrm{SnO}_{2}$.

\section{METHODS}

Computational Methodology. Ab initio density functional theory (DFT) calculations were carried out on $\mathrm{SnO}_{2}$ using a planewave basis within the periodic code, VASP. ${ }^{51-54}$ The projectoraugmented wave method (PAW $)^{55,56}$ was used to describe the interaction between the core electrons $(\mathrm{Sn}[\mathrm{Kr}], \mathrm{O}[\mathrm{He}]$, and $\mathrm{Ta}[\mathrm{Xe}]$ ) and the valence electrons. The hybrid functional used was PBE0 developed by Adamo and Barone, ${ }^{57,58}$ which partially addresses the self-interaction error present in local functionals thus allowing for a better description of the band gap and electronic properties of $\mathrm{SnO}_{2}$. PBE0 incorporates $25 \%$ of exact Fock exchange to the PBE (PerdewBurke-Ernzerhoff $)^{59}$ formalism. For Sn-based TCOs in particular, PBE0 has been shown to yield electronic structure in excellent agreement with experimental results. ${ }^{1,20,60,60-69}$

A full description of all calculations performed is provided in the Supporting Information (SI section 1) and includes the calculation of the formation energies of each defect and its charge state through the methods described by Neugebauer and Van de Walle. ${ }^{70}$ The relative dopant concentrations used in the cells correspond to $\sim 4 \%$ for Ta and $\mathrm{Sb}$ and $\sim 2 \%$ for F, respectively. To account for the finite size effects of the defect supercells, both an image-charge correction and band filling correction were used. The image-charge correction used herein was formulated by Lany and Zunger ${ }^{71}$ and adapted for noncubic systems by Hine et al. ${ }^{72}$ This correction accounts for the interaction of a charged defect with its periodic images. The latter correction remedies the unphysical band filling present in finite-sized supercells in order to regain the dilute limit and is implemented in the scheme by Lany and Zunger. ${ }^{71}$ Simulation of the experimental conditions under which the samples were deposited $(800 \mathrm{~K}, 1 \mathrm{~atm})$ was performed using a formalism developed by Reuter and Scheffler ${ }^{73}$ (SI eq 6), which has been used to successfully simulate F-doped $\mathrm{SnO}_{2}$ films deposited by atmospheric pressure chemical vapor deposition (APCVD) in our previous work. ${ }^{20}$ Due to the folded nature of the energy bands present in large supercells, the band unfolding code "BandUP" by Medeiros et al. ${ }^{7,75}$ was utilized to obtain a primitive cell representation of the band structure of the doped supercells.

Thin Film Fabrication. Thin films of $\mathrm{SnO}_{2}: \mathrm{Ta}$ and $\mathrm{SnO}_{2}: \mathrm{Sb}$ were deposited by aerosol assisted chemical vapor deposition (AACVD). All precursors were purchased from Sigma-Aldrich and used as received. AACVD depositions were carried out on a custom built cold-wall reactor where the substrate $\left(\sim 50 \mathrm{~nm} \mathrm{SiO}{ }_{2}\right.$ barrier-coated float glass) was positioned on a graphite block containing a Watmann 
cartridge heater regulated by a $\mathrm{Pt}-\mathrm{Rh}$ cartridge heater. A stainless steel top plate was positioned $0.8 \mathrm{~cm}$ above the substrate to promote laminar flow. The tantalum doped $\mathrm{SnO}_{2}$ films were grown using a dual pot AACVD process using butyltin trichloride $(0.3 \mathrm{~mL}, 1.77 \mathrm{mmol})$ dissolved in dry methanol $(10 \mathrm{~mL}, 394 \mathrm{mmol})$ and tantalum(V) ethoxide $(5,10,15,20 \mathrm{~mol} \%)$ dissolved in dry toluene $(10 \mathrm{~mL}, 124.7$ $\mathrm{mmol}$ ). The two solutions were atomized using a Johnson Matthey Liquifog piezoelectric ultrasonic humidifier with the tin precursor flow rate kept at $0.6 \mathrm{~L} \mathrm{~min}^{-1}$ using air (BOC, 99.99\%), and the tantalum precursor flow rate was kept at $0.6 \mathrm{~L} \mathrm{~min} \mathrm{~min}^{-1}$ using nitrogen (BOC, 99.99\%). The two flows were then mixed at a $\mathrm{Y}$ junction and delivered to the CVD reactor. The glass substrate was maintained at $500{ }^{\circ} \mathrm{C}$. The antimony doped $\mathrm{SnO}_{2}$ films were grown similar to our previously reported method ${ }^{11}$ on glass substrates at $450{ }^{\circ} \mathrm{C}$ using a one-pot AACVD process where the butyltin trichloride $(0.2 \mathrm{~mL}, 1.06$ mmol) and antimony(III) ethoxide (2, 6, 9, 11, $15 \mathrm{~mol} \%)$ were dissolved in methanol $(10 \mathrm{~mL}, 394 \mathrm{mmol})$. The carrier gas was air, and the flow rate was $1 \mathrm{~L} \mathrm{~min}^{-1}$. At the end of the depositions for both systems, the reactor was turned off and cooled under a flow of nitrogen until $100^{\circ} \mathrm{C}$, after which point the samples were removed. The coated substrates were handled and stored in air.

Thin Film Characterization. Hall effect measurements were carried out in the van der Pauw geometry to determine the sheet resistance, free carrier concentration, and mobility. A square array of Ohmic contacts was arranged on $1 \mathrm{~cm}^{2}$ samples that were subjected to an input current of $1 \mathrm{~mA}$ and a calibrated magnetic field of $0.58 \mathrm{~T}$.

Transmission spectra were obtained using a Shimadzu UV-vis-IR 3700 spectrophotometer with an integrating sphere detector and were measured over a range of $\lambda=250-2500 \mathrm{~nm}$ to cover the visible and near-infrared regions.

Infrared (IR) reflectance measurements were performed using a Bruker Vertex 70v Fourier-transform infrared (FTIR) spectrometer. A $\mathrm{CaF}_{2}$ beam splitter and DLaTGS detector were used, and spectra were recorded over an energy range of $0.25-1.25 \mathrm{eV}$, so the plasma resonance cutoff could be observed for all samples.

Hard X-ray photoemission spectroscopy (HAXPES) was performed at the I09 beamline at the Diamond Light Source (Didcot, UK). A photon energy of $5.95 \mathrm{keV}$ was selected using a $\mathrm{Si}(111)$ double-crystal monochromator and a $\mathrm{Si}(004)$ channel-cut crystal as a post monochromator. The beam size at the sample was $40 \times 20 \mu \mathrm{m}^{2}$ with a grazing incident angle of $87.5^{\circ}$ with respect to the surface normal. Photoelectrons were detected using a EW4000 photoelectron analyzer from VG Scienta (Uppsala, Sweden). Calibration of the binding energy scale was performed using the Fermi edge and the $4 f$ core level lines of a gold reference sample. The gold Fermi edge was fitted to obtain an experimental resolution of $\sim 200 \mathrm{meV}$.

$\mathrm{X}$-ray diffraction (XRD) measurements were collected on a modified Bruker-AXS D8 diffractometer with parallel beam optics fitted with a PSD LynxEye silicon strip detector to collect diffracted $\mathrm{X}$-ray photons. X-rays were generated using a $\mathrm{Cu}$ source with $\mathrm{Cu} \mathrm{K} \alpha_{1}$ and $\mathrm{Cu} \mathrm{K \alpha} \alpha_{2}$ radiation of wavelengths 1.54056 and $1.54439 \AA$, respectively, at an intensity ratio of $2: 1$ and at $40 \mathrm{kV}$ and $30 \mathrm{~mA}$. The incident beam angle was kept at $1^{\circ}$, and the angular range of the patterns collected was $10^{\circ}<2 \theta<65^{\circ}$ with a step size of $0.05^{\circ}$ counted at $0.5 \mathrm{~s}$ per step.

\section{RESULTS AND DISCUSSION}

Defect Thermodynamics and Band Structure. Defect thermodynamics and band structures have been calculated for $\mathrm{Nb}$ and $\mathrm{Ta}$ doped $\mathrm{SnO}_{2}$. As described in detail in the $\mathrm{SI}, \mathrm{Nb}$ is found to be neither a shallow nor a resonant donor. Therefore, the remainder of this work focuses on Ta doping.

To understand why $\mathrm{Ta}$ has the potential to surpass $\mathrm{Sb}$ and $\mathrm{F}$ as a dopant in $\mathrm{SnO}_{2}$, the thermodynamic transition levels of the Ta-related species were calculated and are presented in Figure 1, showing the formation energy of a defect and its respective charge states as a function of Fermi energy. Also shown are the $\mathrm{Sb}$ and $\mathrm{F}$ defect species together with the

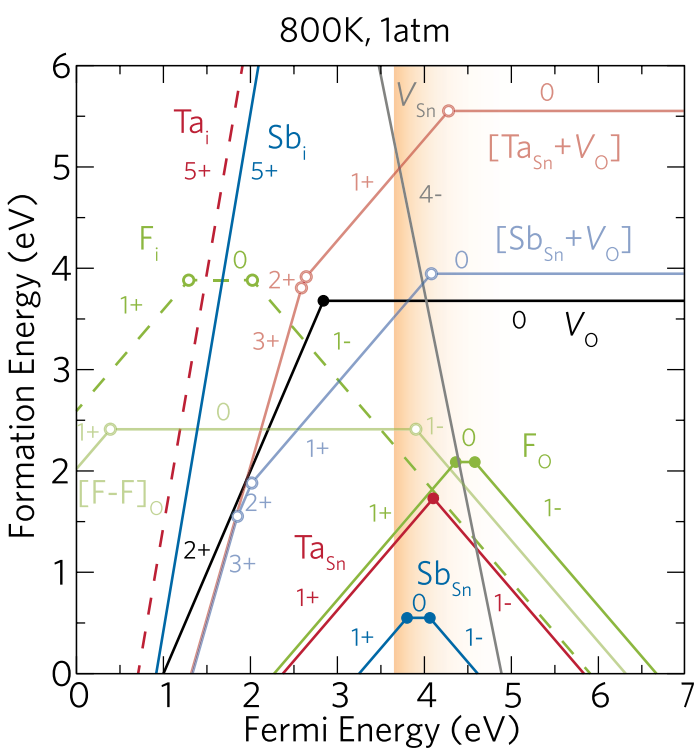

Figure 1. Calculated formation energies for the TaTO (red), ATO (gray), and FTO (green) related defects as a function of Fermi energy under experimental synthesis conditions ( $800 \mathrm{~K}$ and $1 \mathrm{~atm}$ ). The VBM is set at $0 \mathrm{eV}$, and the conduction band is depicted by the graded orange area. A full discussion of the $\mathrm{Sb}$ and $\mathrm{F}$ related defects can be found in refs 11 and 20, respectively.

dominant intrinsic defect species $\left(\mathrm{V}_{\mathrm{Sn}}\right.$ and $\left.\mathrm{V}_{\mathrm{O}}\right)$ as reported previously in refs 11 and 20 . The transition levels shown are presented under $800 \mathrm{~K} / 1$ atm conditions in order to represent the growth conditions of the AACVD grown films in this work.

The substitutional impurity $\mathrm{Ta}_{\mathrm{Sn}}$ is found to be the dominant tantalum species in $\mathrm{SnO}_{2}$ and acts as a resonant one-electron donor transitioning from the +1 charge state to the -1 charge state at around $\sim 0.5 \mathrm{eV}$ above the CBM. These results are in line with the high conductivities seen in the experiment both here and elsewhere. ${ }^{39-49}$

The ability to push the Fermi level high into the conduction band is critical for maximizing the charge carrier concentrations and thus conductivities. In Sb-doped $\mathrm{SnO}_{2}$, despite $\mathrm{Sb}_{\mathrm{Sn}}$ acting as a resonant donor, the +1 charge state transitions to the neutral charge state at $\sim 0.15 \mathrm{eV}$ above the CBM. In Fdoped $\mathrm{SnO}_{2}$, the Fermi level also reaches $\sim 0.5 \mathrm{eV}$ above the CBM before self-compensation from fluorine interstitial defects occurs, thus making Ta competitive as a replacement. ${ }^{20}$ Reaching this Fermi level is also dependent on the solubility of $\mathrm{Ta}$ in $\mathrm{SnO}_{2}$. At the CBM, it can be seen that although $\mathrm{Ta}_{\mathrm{Sn}}$ $(\sim 1.27 \mathrm{eV})$ possesses a higher formation energy than $\mathrm{Sb}_{\mathrm{Sn}}$ $(\sim 0.40 \mathrm{eV})$ at the CBM, it is still lower than $\mathrm{F}_{\mathrm{O}}(\sim 1.33 \mathrm{eV})$. As this level is reachable in FTO thin films, it is highly likely that TaTO thin films will also reach high carrier concentrations. Indeed, it can be expected that under nonequilibrium conditions such as CVD, the solubility will be enhanced due to the inclusion of kinetic effects. ${ }^{76}$

As previously stated, both F-doped $\mathrm{SnO}_{2}$ and $\mathrm{Sb}$-doped $\mathrm{SnO}_{2}$ undergo defect compensation mechanisms that can severely limit the electron mobility and thus the conductivity of tin dioxide. ${ }^{11,20}$ From our calculations, it is shown that the only limiting factor to $\mathrm{Ta}$ as a dopant is the transition to the -1 charge state, whereby $\mathrm{Ta}(\mathrm{V})$ accepts two electrons to become $\mathrm{Ta}$ (III) and thus acts as an acceptor. Additionally, the formation of $\mathrm{Ta}_{\mathrm{i}}$ is prohibitively high $(\sim 13.54 \mathrm{eV}$ in the neutral charge state) under $800 \mathrm{~K} / 1$ atm growth conditions and acts as 
a donor and thus is not expected to form or act as a mechanism for self-compensation.

Similarly, it was found that the clustering of $\mathrm{Ta}_{\mathrm{Sn}}$ and $\mathrm{V}_{\mathrm{O}}$ was highly unfavorable $(\sim 13.54 \mathrm{eV}$ in the neutral charge state), and they preferred to dissociate from each other with the associated formation energy being $\sim 0.38 \mathrm{eV}$ higher for the neutral charge state. Unlike in ATO, therefore, it is highly unlikely that these clusters will exist.

The high mobilities reported in TaTO thin films are indicative of the lack of dopant hybridization at the CBM as seen in Mo-doped $\mathrm{In}_{2} \mathrm{O}_{3}$ (IMO), ${ }^{28,29}$ resulting in no increase in effective mass with increased carrier concentration. The effect of $\mathrm{Ta}$ on the band structure of $\mathrm{SnO}_{2}$ is shown in Figure 2 , which displays the unfolded supercell band structures of

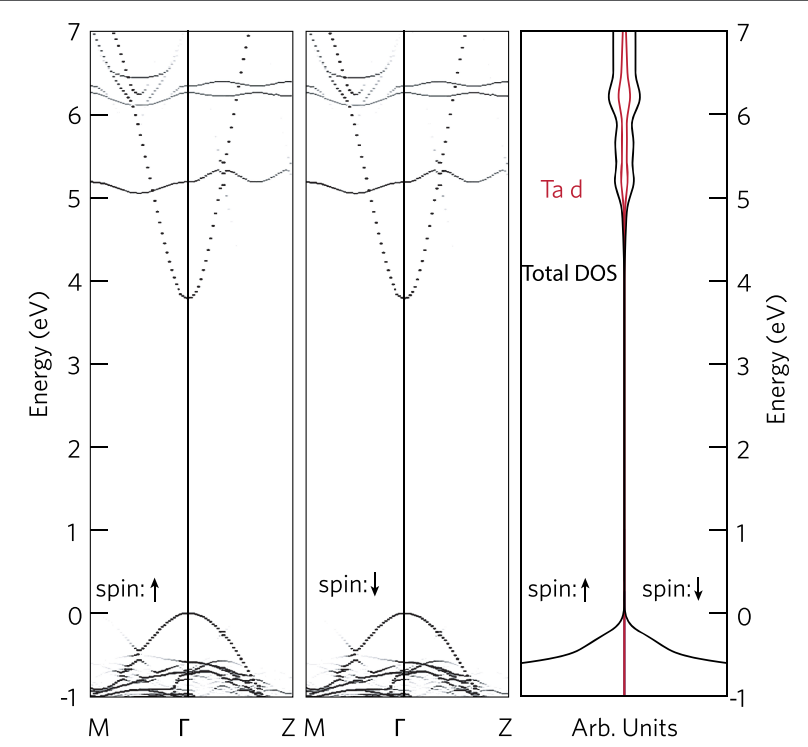

Figure 2. Unfolded band structure and DOS for the ionized (+1 charge state) substitutional $\mathrm{Ta}_{\mathrm{Sn}}$ defect. The band structure is decomposed into both spin-up and spin-down channels, and the VBM is set to $0 \mathrm{eV}$.

substitutional $\mathrm{Ta}\left(\mathrm{Ta}_{\mathrm{Sn}}\right)$ in the +1 (ionized) charge state in both the spin-up and spin-down configurations. Also shown is the density of states (DOS) pertaining to the Ta states. Unfolded band structures are given for $\mathrm{Sb}_{\mathrm{Sn}}$ and $\mathrm{F}_{\mathrm{O}}$ for comparison and are found in SI Figures S3 and S4, respectively.
In both spin-up and spin-down configurations, there is no hybridization of the Ta states with the CBM, which is dominated by $\mathrm{Sn} 5 \mathrm{~s}$ and $\mathrm{O} 2 \mathrm{~s}$ states, which gives rise to its highly dispersive character and low effective mass of $\sim 0.26 \mathrm{~m}_{\mathrm{e}}$ typical of n-type metal oxides. ${ }^{4,11,61,77}$ In TaTO, it can be seen that the Ta $5 \mathrm{~d}$ states occur $\sim 1.40 \mathrm{eV}$ above the CBM in both spin configurations with further $\mathrm{Ta} 5 \mathrm{~d}$ "bands" appearing $\sim 2.47 \mathrm{eV}$ above the CBM. These bands have $70 \% \mathrm{Ta} \mathrm{d}$ character mixed with $\mathrm{Sn} s$ and O s states. For TaTO, the CBM has $<1 \% \mathrm{Ta} \mathrm{d}$ character, indicating minimal perturbation of the $\mathrm{CBM}$ states by Ta doping. Conversely, in the band structures for $\mathrm{Sb}_{\mathrm{Sn}}^{1+}$ and $\mathrm{F}_{\mathrm{O}}^{1+}$ (SI Figures S3 and S4, respectively), there is around $3 \% \mathrm{Sb}$ and $\mathrm{F}$ character at the CBM. This is shown pictorially in Figure $3 \mathrm{a}-\mathrm{c}$ by the partial charge densities of each system (TaTO, ATO, and FTO, respectively) at the CBM. The lack of charge density observed around the $\mathrm{Ta}_{\mathrm{Sn}}$ site (red) indicates there are no Ta states at the CBM. Meanwhile, charge density can been seen around the $\mathrm{Sb}_{\mathrm{Sn}}$ (blue) and $\mathrm{F}_{\mathrm{O}}$ sites, indicating that $\mathrm{Sb}$ and $\mathrm{F}$ contribute states at the CBM. It is clear that for both ATO and FTO, there is significant mixing of the dopant states with those of the host. It is expected, therefore, that no perturbation of the host effective mass will be observed with Ta doping, which gives rise to the high mobilities seen.

\section{EXPERIMENTAL RESULTS}

To experimentally confirm the resonant behavior of $\mathrm{Ta}$ in $\mathrm{SnO}_{2}$ as predicted by the calculations, Ta and $\mathrm{Sb}$ doped $\mathrm{SnO}_{2}$ films were deposited by AACVD. The thin films displayed a wide range of electrical properties as shown in Figure 4 and in Table 1. The samples are labeled by the percentage of $\mathrm{Ta}$ or $\mathrm{Sb}$ in the precursor solution. For the $\mathrm{Sb}$ doped films, the highest mobility is $17.7 \mathrm{~cm}^{2} \mathrm{~V}^{-1} \mathrm{~s}^{-1}$ at a carrier concentration of $3.44 \times$ $10^{20} \mathrm{~cm}^{-3}$, corresponding to the lowest resistivity of $10.3 \times$ $10^{-4} \Omega \mathrm{cm}$. In the $\mathrm{Ta}$ doped films, the highest mobility observed was $25.9 \mathrm{~cm}^{2} \mathrm{~V}^{-1} \mathrm{~s}^{-1}$ at a carrier concentration of $2.65 \times 10^{20} \mathrm{~cm}^{-3}$, corresponding to a resistivity of $9.1 \times$ $10^{-4} \Omega \mathrm{cm}$. Films with a higher carrier density of up to $3.70 \times$ $10^{20} \mathrm{~cm}^{-3}$ and slightly lower mobility gave resistivities down to $7.4 \times 10^{-4} \Omega \mathrm{cm}$. Literature values for TaTO and ATO are also shown in Figure 4. The literature shows a trend of TaTO achieving higher mobilities than ATO at comparable carrier concentrations, similar to the samples studied in this work. Some exceptions to this are the TaTO samples deposited onto a seed layer to promote preferred orientation and increased crystallinity, which display significantly higher mobilities than

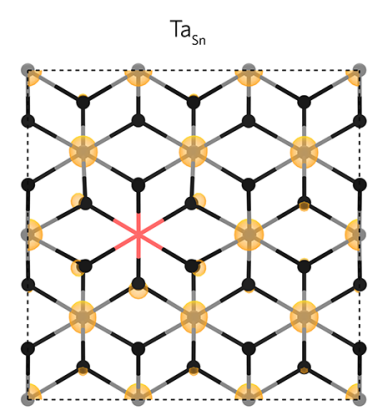

(a)

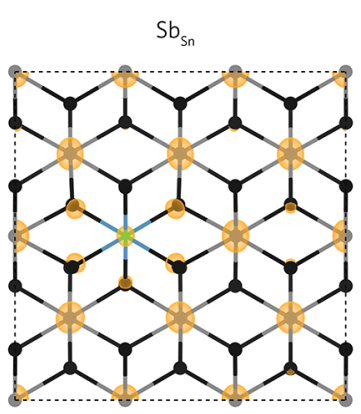

(b)

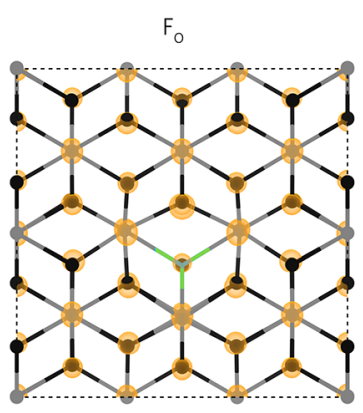

(c)

Figure 3. Partial charge densities at the $\mathrm{CBM}$ of $\mathrm{SnO}_{2}$ for $\mathrm{Ta}_{\mathrm{Sn}}(\mathrm{a}), \mathrm{Sb}_{\mathrm{Sn}}(\mathrm{b})$, and $\mathrm{F}_{\mathrm{O}}(\mathrm{c})$. The densities highlight the fact that $\mathrm{Sb}$ and $\mathrm{F}$ both hybridize with the CBM, thus providing a detrimental effect to the band curvature with increased doping concentrations and that Ta does not undergo this same effect. 


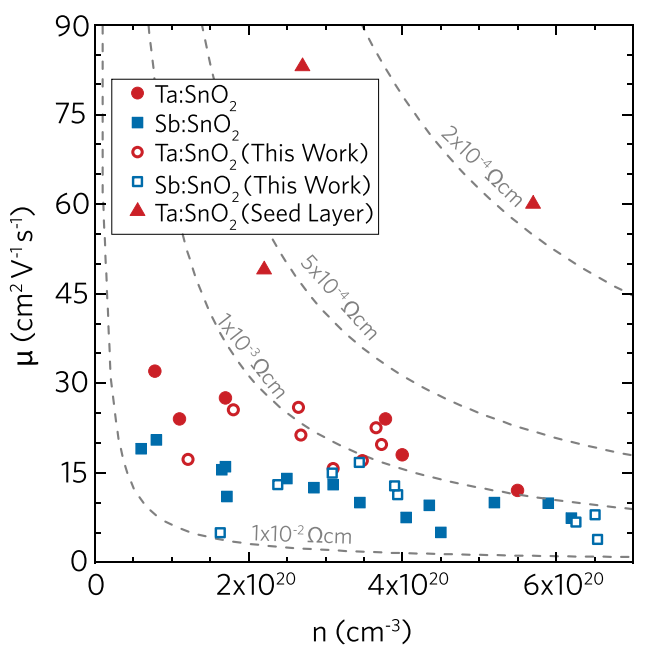

Figure 4. Mobility for samples with a range carrier concentrations deposited by AACVD (This work) and Hall properties of ATO and TaTO samples reported throughout the literature. ${ }^{19,48,78-80}$ Dashed lines display lines of constant resistivity. Triangular points are TaTO films deposited on seed layers as reported in the literature ${ }^{39,50}$

Table 1. Electrical Properties of the "Undoped," Ta-doped and Sb-doped $\mathrm{SnO}_{2}$ Films Used in This Work As Determined by Room Temperature Hall Effect Measurements $^{a}$

\begin{tabular}{|c|c|c|c|c|}
\hline sample & $\begin{array}{l}\text { sheet resistance } \\
(\Omega / \square)\end{array}$ & $\rho(\Omega \mathrm{cm})$ & $\begin{array}{l}\mu\left(\mathrm{cm}^{2}\right. \\
\left.\mathrm{V}^{-1} \mathrm{~s}^{-1}\right)\end{array}$ & $n\left(\mathrm{~cm}^{-3}\right)$ \\
\hline $\begin{array}{l}\text { "undoped" } \\
\mathrm{SnO}_{2}\end{array}$ & 35 & $2.97 \times 10^{-3}$ & 17.2 & $1.21 \times 10^{20}$ \\
\hline $\begin{array}{c}\mathrm{Ta}: \mathrm{SnO}_{2} \\
(5 \%)\end{array}$ & 14 & $1.09 \times 10^{-3}$ & 21.3 & $2.68 \times 10^{20}$ \\
\hline $\begin{array}{c}\mathrm{Ta}: \mathrm{SnO}_{2} \\
(10 \%)\end{array}$ & 8 & $7.42 \times 10^{-4}$ & 22.5 & $3.66 \times 10^{20}$ \\
\hline $\begin{array}{c}\mathrm{Ta}: \mathrm{SnO}_{2} \\
(15 \%)\end{array}$ & 8 & $9.08 \times 10^{-4}$ & 25.9 & $2.65 \times 10^{20}$ \\
\hline $\begin{array}{c}\mathrm{Ta}: \mathrm{SnO}_{2} \\
(20 \%)\end{array}$ & 11 & $8.65 \times 10^{-4}$ & 19.7 & $3.73 \times 10^{20}$ \\
\hline $\begin{array}{l}\mathrm{Ta}: \mathrm{SnO}_{2} \\
\quad(40 \%)\end{array}$ & 13 & $1.29 \times 10^{-3}$ & 15.7 & $3.10 \times 10^{20}$ \\
\hline $\begin{array}{c}\mathrm{Sb}: \mathrm{SnO}_{2} \\
(2 \%)\end{array}$ & 11 & $1.03 \times 10^{-3}$ & 17.7 & $3.44 \times 10^{20}$ \\
\hline $\begin{array}{c}\mathrm{Sb}: \mathrm{SnO}_{2} \\
(6 \%)\end{array}$ & 23 & $1.40 \times 10^{-3}$ & 11.3 & $3.94 \times 10^{20}$ \\
\hline $\begin{array}{l}\mathrm{Sb}: \mathrm{SnO}_{2} \\
(9 \%)\end{array}$ & 33.5 & $1.49 \times 10^{-3}$ & 13.0 & $2.38 \times 10^{20}$ \\
\hline $\begin{array}{c}\mathrm{Sb}: \mathrm{SnO}_{2} \\
(11 \%)^{2}\end{array}$ & 128 & $7.72 \times 10^{-3}$ & 5.0 & $1.63 \times 10^{20}$ \\
\hline $\begin{array}{c}\mathrm{Sb}: \mathrm{SnO}_{2} \\
(15 \%)\end{array}$ & 23 & $1.49 \times 10^{-3}$ & 6.7 & $6.26 \times 10^{20}$ \\
\hline
\end{tabular}

$(15 \%)^{2}$

${ }^{a}$ Percentages given are the $\mathrm{Ta}$ or $\mathrm{Sb}$ concentration in the precursor solution.

seen elsewhere and highlight the potential of $\mathrm{Ta}$ as a dopant. $^{39,50}$

X-ray diffraction patterns are displayed in Figure S5 and are discussed in the text of the Supporting Information.

Experimentally, the difference in the conduction band dispersion expected due to differences in hybridization with the Sn 5s states can be observed as changes in band filling as a function of carrier density. This can also be seen as a difference in the electron effective mass, as the carrier effective mass and band dispersion are related.
Transmission spectra for examples of TaTO and ATO of comparable carrier concentrations, $3.66 \times 10^{20}$ and $3.44 \times$ $10^{20} \mathrm{~cm}^{-3}$, respectively, are shown in Figure 5a. The transmission at high energies is comparable for the two samples. However, at lower energies, TaTO displays superior transmission. For photovoltaic application, depending on the absorber used, transparency in the near-infrared at energies as low as $1.1 \mathrm{eV}$ can be important. Currently, one of the main applications of FTO is as a transparent electrode in thin film solar cells, so it is likely that commercially TaTO would be used in similar applications, so the increased transmission in the near-IR is important. It should be noted that $\mathrm{Zr}$-doped $\mathrm{In}_{2} \mathrm{O}_{3}$ thin films with improved IR transparency have been reported to yield an improvement in power conversion efficiency of perovksite solar cells, due to the lack of parasitic losses in the IR region. ${ }^{81}$

The reflectivity spectra in the near IR range for the same samples is shown in Figure $5 \mathrm{~b}$. Reflectivity in this range is caused by scattering of light by free carriers, and the onset of reflection is determined by the plasma frequency, $\omega_{\mathrm{p}}$. The energy at which this onset occurs is described by

$$
\omega_{\mathrm{p}}=\sqrt{\frac{n e^{2}}{m^{*} \epsilon_{\infty} \epsilon_{0}}}
$$

For these samples of similar carrier concentration, the ATO sample has a reflection onset at a lower energy than the TaTO sample. On the basis of eq 1 , this must be due to variation in the carrier effective mass. As $\omega_{\mathrm{p}}$ is proportional to the inverse of the square route of $m^{*}$, a higher plasma frequency is expected for a lower effective mass. This is indicative that carriers in ATO have a higher effective mass than those in TaTO.

When comparing TaTO and ATO films of equal conductivity, the TaTO films with higher mobility, $\mu$, will have lower carrier density, $n$, as conductivity, $\sigma$, is given by $\sigma=$ $n e \mu$. This lower $n$ leads to lower conduction electron plasma frequency and so increased infrared transparency.

Differences in band filling can be observed as changes in the relationship between the Fermi level and carrier concentration in the film. It was not possible to optically measure the gap for the samples in this study as the absorption edge of the glass substrate is at a lower energy than that of the doped $\mathrm{SnO}_{2}$ films. However, the Fermi level to valence band maximum separation, $\Phi=E_{\mathrm{F}}-E_{\mathrm{V}}$, can be be observed in the HAXPES spectra, as emission from the conduction band up to the Fermi level can be observed, as shown in Figure $6 a$ and $b$. The value obtained will be close to the optical band gap, $E_{\text {opt }}$ but will vary from it slightly as valence band dispersion does not contribute to $\Phi$, as illustrated in Figure 6d. A full description of how the $\Phi$ values were obtained is given in the Supporting Information. HAXPES is used rather than conventional XPS due to the increased relative cross-section of s states compared with $\mathrm{p}$ and $\mathrm{d}$ states at higher photon energies and the increased intensity obtained from synchotron radiation. As the conduction band minimum is primarily of $\mathrm{Sn} 5$ s character, the relative intensity of the signal from the conduction band is therefore a lot higher in HAXPES. This enables the $\Phi$ values to be determined more easily, and the results are plotted in Figure $6 c$.

The carrier concentration, $n$, of the films is related to the Fermi energy, $E_{\mathrm{F}}$, by 


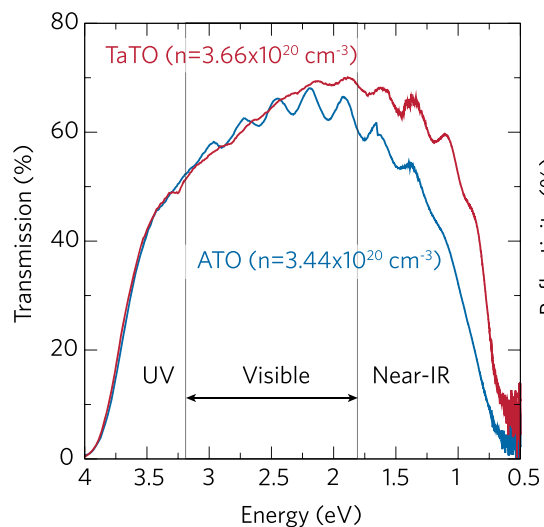

(a)

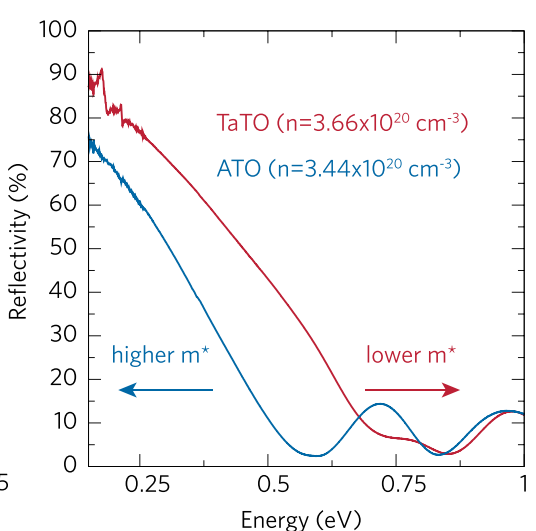

(b)

Figure 5. (a) The wide range transmission spectra for TaTO and ATO samples with carrier concentrations of $3.66 \times 10^{20}$ and $3.44 \times 10^{20} \mathrm{~cm}^{-3}$ respectively. (b) The IR reflectivity spectra for the same two samples showing different onsets for the plasma edge. The expressions for plasma frequency are shown, showing that at constant carrier concentrations the plasma frequency will depend on the inverse of the carrier effective mass.
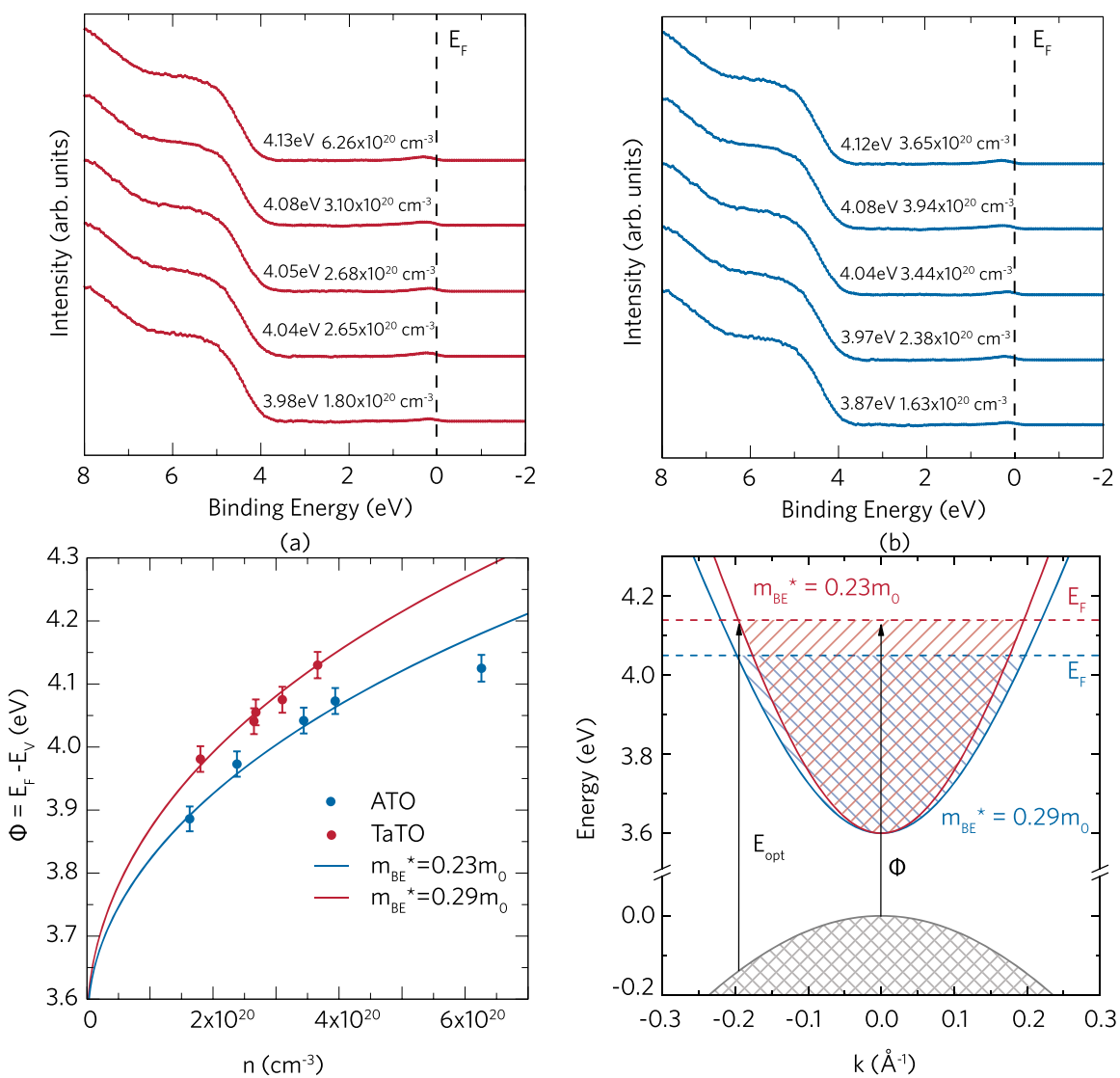

(c)

(d)

Figure 6. The fitted VB edges for HAXPES spectra for a range of carrier concentrations in (a) TaTO and (b) ATO. A Fermi edge has been fitted to the conduction band emission in each spectrum and set to $0 \mathrm{eV}$. The values presented are $\Phi$ for each data set. (c) The optical gaps as calculated from valence band and conduction band HAXPES spectra of TaTO and ATO film with a range of carrier concentrations. Fitted lines are calculated using the nonparabolic alpha approximation. (d) The calculated band dispersion for band edge effective masses $0.23 m_{0}$ (red) and $0.29 m_{0}$ (blue) demonstrating the difference in band filling by showing the differnt Fermi levels (dashed lines) for a carrier concentration of $3.6 \times 10^{20} \mathrm{~cm}^{-3}$. The optical gap, $E_{\text {opt }}$ and the Fermi level to VBM separation, $\Phi$, are demonstrated for the band edge effective mass of $0.23 m_{0}$.

$$
n=\int_{0}^{\infty} D(E) f(E) \mathrm{d} E
$$

where $D(E)$ is the energy dependent density of states and $f(E)$ a Fermi function which is dependent on $E_{\mathrm{F}} . D(E)$ is dependent on $\mathrm{m}^{*}$; therefore the relationship between carrier concen- tration and Fermi level is dependent on the carrier effective mass.

The carrier concentrations of the samples are known from Hall effect measurements and are plotted against $\Phi$ in Figure 6c. A clear difference between the relationships between $E_{\text {opt }}$ and $n$ for the two differently doped materials can be seen with 
higher Fermi levels being observed for similar carrier concentrations in TaTO compared to ATO.

$\Phi$ was calculated as a function of $n$ using eq 2 for a range of band edge effective masses, $m_{\mathrm{BE}}{ }^{*}$, while accounting for conduction band nonparabolicity using the alpha approximation. ${ }^{82}$ The calculated lines that fit the data are shown in Figure $6 \mathrm{c}$, and the values of $m_{\mathrm{BE}} *$ for TaTO and ATO were found to be $0.23 m_{0}$ and $0.29 m_{0}$, respectively.

Figure $6 \mathrm{~d}$ shows the calculated band dispersion, using the alpha approximation, where $E(1+\alpha E)=\hbar^{2} k^{2} / 2 m_{0} *$ and $\alpha=$ $1 / E_{g}$, to account for nonparabolicity, for the effective masses obtained for TaTO and ATO. An increase in band edge effective mass is shown to result in a more dispersed conduction band. The Fermi levels shown are calculated for a carrier concentration of $3.6 \times 10^{20} \mathrm{~cm}^{-3}$.

The different $\mathrm{CB}$ dispersion should result in discernible differences in HAXPES CB emission as previously shown for a comparison of IMO and ITO. ${ }^{29}$ However, the presence of $\mathrm{Sn}$ (II) lone pairs introduces intense subgap states, the intensity of which merges into the weak $\mathrm{CB}$ emission, as shown in Figure SS6 in the SI. This makes detailed comparisons of the conduction band emission as a function of carrier density and dopant type impossible in this case.

The increase in the band edge effective mass and change in dispersion in ATO compared to TaTO is due to hybridization of the $\mathrm{Sb} \mathrm{5s}$ with the $\mathrm{Sn} 5 \mathrm{~s}$ at the conduction band minimum. Notably, the ATO sample with the highest carrier concentration does not fall on the fitted line for $m_{\mathrm{BE}}{ }^{*}=0.29 m_{0}$ in Figure $6 \mathrm{c}$. This is likely due to higher $\mathrm{Sb}$ incorporation causing further hybridization with the CBM, further increasing the band-edge effective mass.

While these values can explain the increase in mobility observed in these Ta doped AACVD films with respect to $\mathrm{Sb}$ doping, the differences in effective mass are not enough to explain the high mobilities observed in previous literature. It is of note that the highest mobility samples reported in the literature have all been grown on seed layers promoting a (100) preferred orientation and increased grain size. ${ }^{39,50}$ While the mechanism behind these higher mobilities is not fully understood, as, at the high carrier concentrations observed, grain-boundary scattering is expected to have minimal contribution, ${ }^{83}$ these samples highlight the potential of TaTO to surpass other $\mathrm{SnO}_{2}$-based TCOs. While CVD FTO has benefitted from decades of empirical optimization, it has reached the peak of its self-compensation-limited performance. $^{20}$ Meanwhile, CVD of TaTO is in its infancy, but our results and those from other deposition techniques ${ }^{39,43,50}$ indicate that the conductivity of CVD TaTO could exceed that of FTO by a factor of 5 or 6 with improved IR transparency.

Bhachu et al. suggested that the mechanism for the improved mobilities seen in IMO compared to ITO was "remote ionized impurity scattering." ${ }^{28}$ In the paper, it is suggested that, as the donor state was significantly energetically removed from the CBM, the CBM wave function will be weak close to the donor atom. As a result, the conduction electrons would experience reduced scattering by the donor center's Coulomb potential in comparison to a nonresonant donor. For this mechanism to make a difference in Ta doped $\mathrm{SnO}_{2}$, the atomic distance between the $\mathrm{Ta}$ donor atoms and the $\mathrm{Sn}$ atoms, $d$, would need to be comparable or greater than the Thomas-Fermi screening length, $\lambda_{\mathrm{TF}}$. The reduction in Coulombic interaction can be expected to be a factor of $\exp \left(-d / \lambda_{\mathrm{TF}}\right)$. The separation of Ta from $\mathrm{Sn}$ atoms is about 3.1
$\AA$ (ref 84), and the Thomas-Fermi screening length is around $7.0 \AA$ for a carrier concentration of around $3 \times 10^{20} \mathrm{~cm}^{-3}$. These values give a factor 0.64 times for Coulomb scattering by donor centers in $\mathrm{Ta}$ doped $\mathrm{SnO}_{2}$ compared to regular donor impurities such as $\mathrm{Sb}$. This corresponds to an increased ionized impurity limited mobility of $1 / 0.64$ or 1.56 times. This difference closely matches the difference in mobility seen in the ATO and TaTO samples studied in this work.

These observations made from the HAXPES data in combination with the results from DFT calculations show clear benefits of the position of the $\mathrm{Ta}$ donor states with respect to the CBM. The Ta $\mathrm{d}$ states sit resonant in the conduction band, meaning that there is minimal mixing with the host states at the CBM. As a result, the shape of the conduction band is maintained and carrier effective mass is not increased as occurs with traditional dopants, and higher mobilities can be achieved.

\section{CONCLUSION}

Using a combination of hybrid density functional theory calculations, IR reflectivity, and hard X-ray photoelectron spectroscopy, we have demonstrated conclusively that $\mathrm{Ta}$ is a resonant donor in $\mathrm{SnO}_{2}$. These findings, in combination with previous literature on Ta-doped $\mathrm{SnO}_{2}$, indicate that $\mathrm{Ta}$ is a superior dopant to both fluorine and antimony, with the capability to yield higher conductivities, higher mobilities, and better IR transparency than either FTO or ATO. These findings suggest that $\mathrm{TaTO}$ has the potential to replace FTO as the industrial standard for large surface area applications where a low cost TCO is required.

\section{ASSOCIATED CONTENT}

\section{Supporting Information}

The Supporting Information is available free of charge at https://pubs.acs.org/doi/10.1021/acs.chemmater.9b04845.

Computational methodology, $\mathrm{Nb}$-doped $\mathrm{SnO}_{2}$, unfolded bandstructures of ATO and FTO, XRD, HAXPEX midgap states, and the full method for experimentally determining Fermi level to VBM separation (PDF)

\section{AUTHOR INFORMATION}

\section{Corresponding Authors}

Tim D. Veal - Stephenson Institute for Renewable Energy and Department of Physics, University of Liverpool, Liverpool L69 7ZF, United Kingdom; 이이.org/0000-0002-0610-5626; Email: T.Veal@liverpool.ac.uk

David O. Scanlon - Department of Chemistry and Thomas Young Centre, University College London, London WC1H OAJ, United Kingdom; (1) orcid.org/0000-0001-9174-8601; Email: d.scanlon@ucl.ac.uk

\section{Authors}

Benjamin A. D. Williamson - Department of Chemistry and Thomas Young Centre, University College London, London WC1H OAJ, United Kingdom; o orcid.org/0000-0002-62421121

Thomas J. Featherstone - Stephenson Institute for Renewable Energy and Department of Physics, University of Liverpool, Liverpool L69 7ZF, United Kingdom

Sanjayan S. Sathasivam - Materials Research Centre, Chemistry Department, University College London, London WC1H OAJ, United Kingdom; ○ orcid.org/0000-0002-5206-9558 
Jack E. N. Swallow - Stephenson Institute for Renewable Energy and Department of Physics, University of Liverpool, Liverpool L69 7ZF, United Kingdom

Huw Shiel - Stephenson Institute for Renewable Energy and Department of Physics, University of Liverpool, Liverpool L69 7ZF, United Kingdom

Leanne A. H. Jones - Stephenson Institute for Renewable Energy and Department of Physics, University of Liverpool, Liverpool L69 7ZF, United Kingdom

Matthew J. Smiles - Stephenson Institute for Renewable Energy and Department of Physics, University of Liverpool, Liverpool L69 7ZF, United Kingdom

Anna Regoutz - Department of Chemistry, University College London, London WC1H OAJ, United Kingdom; ㅈorcid.org/ 0000-0002-3747-3763

Tien-Lin Lee - Diamond Light Source Ltd., Diamond House, Harwell Science and Innovation Campus, Didcot, Oxfordshire OX11 ODE, United Kingdom

Xueming Xia - Department of Chemistry, University College London, London WC1H OAJ, United Kingdom

Christopher Blackman - Department of Chemistry, University College London, London WC1H OAJ, United Kingdom; (1) orcid.org/0000-0003-0700-5843

Pardeep K. Thakur - Diamond Light Source Ltd., Diamond House, Harwell Science and Innovation Campus, Didcot, Oxfordshire OX11 ODE, United Kingdom; (1) orcid.org/00000002-9599-0531

Claire J. Carmalt - Materials Research Centre, Chemistry Department, University College London, London WC1H OAJ, United Kingdom; 이이.org/0000-0003-1788-6971

Ivan P. Parkin - Materials Research Centre, Chemistry Department, University College London, London WC1H OAJ, United Kingdom

Complete contact information is available at:

https://pubs.acs.org/10.1021/acs.chemmater.9b04845

\section{Author Contributions}

${ }^{\#}$ Contributed equally to this work

\section{Notes}

The authors declare no competing financial interest.

\section{ACKNOWLEDGMENTS}

This work was supported by the Engineering and Physical Sciences Research Council (EPSRC) [grant numbers EP/ N01572X/1 and EP/N015800/1]. T.J.F., J.E.N.S., and M.J.S. acknowledge studentship support from the EPSRC Centre for Doctoral Training in New and Sustainable Photovoltaics (Grant No. EP/L01551X/1). H.S. studentship was funded by the EPSRC (Grant No. EP/N509693/1). L.A.H.J.'s studentship was funded by the EPSRC Doctoral Training Partnership (Grant No. EP/R513271/1). The authors thank Diamond Light source for providing beam time and facilities under proposals SI18195-1 and SI21431-1. We are grateful to the UK Materials and Molecular Modelling Hub for computational resources, which is partially funded by EPSRC (EP/P020194/ 1) and to UCL for the provision of the Legion, Myriad, and Grace supercomputers. Via our membership of the UK's HEC Materials Chemistry Consortium, which is funded by EPSRC (EP/L000202, EP/R029431), this work used the ARCHER UK National Supercomputing Service (http://www.archer.ac. uk). D.O.S. and T.D.V. acknowledge membership of the Materials Design Network. NSG Group are acknowledged for useful discussions and for supplying glass substrates used in this work.

\section{REFERENCES}

(1) Hosono, H. Recent progress in transparent oxide semiconductors: Materials and device application. Thin Solid Films 2007, 515, 6000-6014.

(2) Stadler, A. Transparent Conducting Oxides - An Up-To-Date Overview. Materials 2012, 5, 661-683.

(3) Lewis, B. G.; Paine, D. C. Applications and Processing of Transparent Conducting Oxides. MRS Bull. 2000, 25, 22-27.

(4) Dixon, S. C.; Scanlon, D. O.; Carmalt, C. J.; Parkin, I. P. N-Type doped transparent conducting binary oxides: an overview. J. Mater. Chem. C 2016, 4, 6946-6961.

(5) Parkin, I. P.; Manning, T. D. Intelligent Thermochromic Windows. J. Chem. Educ. 2006, 83, 393-400.

(6) Das, S.; Jayaraman, V. $\mathrm{SnO}_{2}$ : A comprehensive review on structures and gas sensors. Prog. Mater. Sci. 2014, 66, 112-255.

(7) Aliyu, M. M.; Hossain, S.; Husna, J.; Dhar, N.; Huda, M. Q.; Sopian, K.; Amin, N. High quality indium tin oxide (ITO) film growth by controlling pressure in RF magnetron sputtering. 2012 38th IEEE Photovoltaic Specialists Conference; IEEE, 2012; pp 002009002013.

(8) Gupta, R.; Ghosh, K.; Mishra, S.; Kahol, P. Structural, optical and electrical characterization of highly conducting Mo-doped $\mathrm{In}_{2} \mathrm{O}_{3}$ thin films. Appl. Surf. Sci. 2008, 254, 4018-4023.

(9) Minami, T. New n-Type Transparent Conducting Oxides. MRS Bull. 2000, 25, 38-44.

(10) Batzill, M.; Diebold, U. The surface and materials science of tin oxide. Prog. Surf. Sci. 2005, 79, 47-154.

(11) Ponja, S. D.; Williamson, B. A. D.; Sathasivam, S.; Scanlon, D. O.; Parkin, I. P.; Carmalt, C. J. Enhanced electrical properties of antimony doped tin oxide thin films deposited via aerosol assisted chemical vapour deposition. J. Mater. Chem. C 2018, 6, 7257-7266.

(12) Abendroth, T.; Schumm, B.; Alajlan, S. A.; Almogbel, A. M.; Mäder, G.; Härtel, P.; Althues, H.; Kaskel, S. Optical and thermal properties of transparent infrared blocking antimony doped tin oxide thin films. Thin Solid Films 2017, 624, 152-159.

(13) Kim, H.; Auyeung, R.; Piqué, A. Transparent conducting Fdoped $\mathrm{SnO}_{2}$ thin films grown by pulsed laser deposition. Thin Solid Films 2008, 516, 5052-5056.

(14) Marcel, C.; Hegde, M.; Rougier, A.; Maugy, C.; Guéry, C.; Tarascon, J.-M. Electrochromic properties of antimony tin oxide (ATO) thin films synthesized by pulsed laser deposition. Electrochim. Acta 2001, 46, 2097-2104.

(15) Zhi, X.; Zhao, G.; Zhu, T.; Li, Y. The morphological, optical and electrical properties of $\mathrm{SnO}_{2}: \mathrm{F}$ thin films prepared by spray pyrolysis. Surf. Interface Anal. 2008, 40, 67-70.

(16) Bisht, H.; Eun, H.-T.; Mehrtens, A.; Aegerter, M. Comparison of spray pyrolyzed FTO, ATO and ITO coatings for flat and bent glass substrates. Thin Solid Films 1999, 351, 109-114.

(17) Han, C.-H.; Han, S.-D.; Gwak, J.; Khatkar, S. Synthesis of indium tin oxide (ITO) and fluorine-doped tin oxide (FTO) nanopowder by sol-gel combustion hybrid method. Mater. Lett. 2007, 61, $1701-1703$.

(18) Terrier, C.; Chatelon, J.; Roger, J. Electrical and optical properties of $\mathrm{Sb}: \mathrm{SnO}_{2}$ thin films obtained by the sol-gel method. Thin Solid Films 1997, 295, 95-100.

(19) Bissig, B.; Jäger, T.; Ding, L.; Tiwari, A. N.; Romanyuk, Y. E. Limits of carrier mobility in Sb-doped $\mathrm{SnO}_{2}$ conducting films deposited by reactive sputtering. APL Mater. 2015, 3, 062802.

(20) Swallow, J. E. N.; Williamson, B. A. D.; Whittles, T. J.; Birkett, M.; Featherstone, T. J.; Peng, N.; Abbott, A.; Farnworth, M.; Cheetham, K. J.; Warren, P.; Scanlon, D. O.; Dhanak, V. R.; Veal, T. D. Self-Compensation in Transparent Conducting F-Doped $\mathrm{SnO}_{2}$. Adv. Funct. Mater. 2018, 28, 1701900.

(21) White, M. E.; Bierwagen, O.; Tsai, M. Y.; Speck, J. S. Electron transport properties of antimony doped $\mathrm{SnO}_{2}$ single crystalline thin 
films grown by plasma-assisted molecular beam epitaxy. J. Appl. Phys. 2009, 106, 093704.

(22) Berry, F. J.; Laundy, B. J. Note. Antimony-121 Mössbauer study of the effects of calcination on the structure of tin-antimony oxides. J. Chem. Soc., Dalton Trans. 1981, 1442-1444.

(23) Gržeta, B.; Tkalčec, E.; Goebbert, C.; Takeda, M.; Takahashi, M.; Nomura, K.; Jakšić, M. Structural studies of nanocrystalline $\mathrm{SnO} 2$ doped with antimony: XRD and Mössbauer spectroscopy. J. Phys. Chem. Solids 2002, 63, 765-772.

(24) Terrier, C.; Chatelon, J.; Roger, J.; Berjoan, R.; Dubois, C. Analysis of Antimony Doping in Tin Oxide Thin Films Obtained by the Sol-Gel Method. J. Sol-Gel Sci. Technol. 1997, 10, 75-81.

(25) Montilla, F.; Morallon, E.; De Battisti, A.; Barison, S.; Daolio, S.; Vazquez, J. L. Preparation and Characterization of AntimonyDoped Tin Dioxide Electrodes. 3. XPS and SIMS Characterization. J. Phys. Chem. B 2004, 108, 15976-15981.

(26) Geraldo, V.; Briois, V.; Scalvi, L.; Santilli, C. EXAFS investigation on $\mathrm{Sb}$ incorporation effects to electrical transport in $\mathrm{SnO}_{2}$ thin films deposited by sol-gel. J. Eur. Ceram. Soc. 2007, 27, $4265-4268$.

(27) Rockenberger, J.; zum Felde, U.; Tischer, M.; Tröger, L.; Haase, M.; Weller, H. Near edge X-ray absorption fine structure measurements (XANES) and extended $\mathrm{x}$-ray absorption fine structure measurements (EXAFS) of the valence state and coordination of antimony in doped nanocrystalline $\mathrm{SnO}_{2}$. J. Chem. Phys. 2000, 112, $4296-4304$.

(28) Bhachu, D. S.; Scanlon, D. O.; Sankar, G.; Veal, T. D.; Egdell, R. G.; Cibin, G.; Dent, A. J.; Knapp, C. E.; Carmalt, C. J.; Parkin, I. P. Origin of High Mobility in Molybdenum-Doped Indium Oxide. Chem. Mater. 2015, 27, 2788-2796.

(29) Swallow, J. E. N.; et al. Resonant Doping for High Mobility Transparent Conductors: the Case of Mo-doped $\operatorname{In}_{2} \mathrm{O}_{3}$. Mater. Horiz. 2020, 7, 236-243.

(30) Walsh, A.; Sokol, A. A.; Buckeridge, J.; Scanlon, D. O.; Catlow, C. R. A. Oxidation states and ionicity. Nat. Mater. 2018, 17, 958-964.

(31) Abe, Y.; Ishiyama, N. Titanium-doped indium oxide films prepared by d.c. magnetron sputtering using ceramic target. J. Mater. Sci. 2006, 41, 7580-7584.

(32) Morales-Masis, M.; Rucavado, E.; Monnard, R.; Barraud, L.; Holovsky, J.; Despeisse, M.; Boccard, M.; Ballif, C. Highly conductive and boradband transparent $\mathrm{Zr}$-doped $\operatorname{In}_{2} \mathrm{O}_{3}$ as front electrode for solar cell. IEEE journal of photovolatics 2018, 8, 1202-1207.

(33) Wang, G.; Shi, C.; Zhao, L.; Diao, H.; Wang, W. Transparent conductive Hf-doped In $2 \mathrm{O} 3$ thin films by RF sputtering technique at low temperature annealing. Appl. Surf. Sci. 2017, 399, 716-720.

(34) Abe, Y.; Ishiyama, N. Polycrystalline films of tungsten-doped indium oxide prepared by d.c. magnetron sputtering. Mater. Lett. 2007, 61, 566-569.

(35) Egdell, R. G.; Gulino, A.; Rayden, C.; Peacock, G.; Cox, P. A. Nature of donor states in V-doped $\mathrm{SnO}_{2}$. J. Mater. Chem. 1995, 5, 499-504.

(36) Suzuki, A. Y.; Nose, K.; Ueno, A.; Kamiko, M.; Mitsuda, Y. High Transparency and Electrical Conductivity of $\mathrm{SnO}_{2}: \mathrm{Nb}$ Thin Films Formed through (001)-Oriented $\mathrm{SnO}: \mathrm{Nb}$ on Glass Substrate. Appl. Phys. Express 2012, 5, 011103.

(37) Gokulakrishnan, V.; Parthiban, S.; Jeganathan, K.; Ramamurthi, $\mathrm{K}$. Investigations on the structural, optical and electrical properties of $\mathrm{Nb}$-doped $\mathrm{SnO}_{2}$ thin films. J. Mater. Sci. 2011, 46, 5553-5558.

(38) Seo, Y. J.; Kim, G. W.; Sung, C. H.; Anwar, M.; Lee, C. G.; Koo, B. H. Characterization of transparent and conductive electrodes of $\mathrm{Nb}$-doped $\mathrm{SnO}_{2}$ thin film by pulsed laser deposition. Curr. Appl. Phys. 2011, 11, S310-S313.

(39) Nakao, S.; Yamada, N.; Hitosugi, T.; Hirose, Y.; Shimada, T.; Hasegawa, T. High Mobility Exceeding $80 \mathrm{~cm}^{2} \mathrm{~V}^{-1} \mathrm{~s}^{-1}$ in Polycrystalline Ta-Doped $\mathrm{SnO}_{2}$ Thin Films on Glass Using Anatase $\mathrm{TiO}_{2}$ Seed Layers. Appl. Phys. Express 2010, 3, 031102.

(40) Lee, S. W.; Kim, Y.-W.; Chen, H. Electrical properties of Tadoped $\mathrm{SnO}_{2}$ thin films prepared by the metal-organic chemical-vapor deposition method. Appl. Phys. Lett. 2001, 78, 350-352.
(41) Kim, Y.-W.; Lee, S. W.; Chen, H. Microstructural evolution and electrical property of Ta-doped $\mathrm{SnO}_{2}$ films grown on $\mathrm{Al}_{2} \mathrm{O}_{3}$ (0001) by metalorganic chemical vapor deposition. Thin Solid Films 2002, 405, $256-262$.

(42) Lee, S.; Daga, A.; Xu, Z.; Chen, H. Characterization of MOCVD grown optical coatings of $\mathrm{Sc}_{2} \mathrm{O}_{3}$ and Ta-doped $\mathrm{SnO}_{2}$. Mater. Sci. Eng., B 2003, 99, 134-137.

(43) Nakao, S.; Yamada, N.; Hitosugi, T.; Hirose, Y.; Shimada, T.; Hasegawa, T. Fabrication of highly conductive Ta-doped $\mathrm{SnO}_{2}$ polycrystalline films on glass using seed-layer technique by pulse laser deposition. Thin Solid Films 2010, 518, 3093-3096.

(44) Toyosaki, H.; Kawasaki, M.; Tokura, Y. Electrical properties of Ta-doped $\mathrm{SnO}_{2}$ thin films epitaxially grown on $\mathrm{TiO}_{2}$ substrate. Appl. Phys. Lett. 2008, 93, 132109.

(45) Turgut, G. Effect of Ta doping on the characteristic features of spray-coated $\mathrm{SnO}_{2}$. Thin Solid Films 2015, 594, 56-66.

(46) Muto, Y.; Nakatomi, S.; Oka, N.; Iwabuchi, Y.; Kotsubo, H.; Shigesato, Y. High-rate deposition of Ta-doped $\mathrm{SnO}_{2}$ films by reactive magnetron sputtering using a $\mathrm{Sn}-\mathrm{Ta}$ metal-sintered target. Thin Solid Films 2012, 520, 3746-3750.

(47) Nguyen, N. M.; Luu, M. Q.; Nguyen, M. H.; Nguyen, D. T.; Bui, V. D.; Truong, T. T.; Pham, V. T.; Nguyen-Tran, T. Synthesis of Tantalum-Doped Tin Oxide Thin Films by Magnetron Sputtering for Photovoltaic Applications. J. Electron. Mater. 2017, 46, 3667-3673.

(48) Weidner, M.; Jia, J.; Shigesato, Y.; Klein, A. Comparative study of sputter-deposited $\mathrm{SnO}_{2}$ films doped with antimony or tantalum. Phys. Status Solidi B 2016, 253, 923-928.

(49) Weidner, M.; Brötz, J.; Klein, A. Sputter-deposited polycrystalline tantalum-doped $\mathrm{SnO}_{2}$ layers. Thin Solid Films 2014, 555, 173178.

(50) Yamada, N.; Nakao, S.; Hitosugi, T.; Hasegawa, T. Sputter Deposition of High-Mobility $\mathrm{Sn}_{1-x} \mathrm{Ta}_{x} \mathrm{O}_{2}$ Films on Anatase- $\mathrm{TiO}_{2^{-}}$ Coated Glass. Jpn. J. Appl. Phys. 2010, 49, 108002.

(51) Kresse, G.; Hafner, J. Ab-initio molecular-dynamics simulation of the liquid-metal-amorphous-semiconductor transition in germanium. Phys. Rev. B: Condens. Matter Mater. Phys. 1994, 49, 1425114269.

(52) Kresse, G.; Hafner, J. Ab-initio molecular dynamics for liquid metals. Phys. Rev. B: Condens. Matter Mater. Phys. 1993, 47, 558-561.

(53) Kresse, G.; Furthmüller, J. Efficiency of ab-initio total energy calculations for metals and semiconductors using a plane-wave basis set. Comput. Mater. Sci. 1996, 6, 15-50.

(54) Kresse, G.; Furthmüller, J. Efficient iterative schemes forab initiototal-energy calculations using a plane-wave basis set. Phys. Rev. B: Condens. Matter Mater. Phys. 1996, 54, 11169-11186.

(55) Blöchl, P. E. Projector augmented-wave method. Phys. Rev. B: Condens. Matter Mater. Phys. 1994, 50, 17953-17979.

(56) Kresse, G.; Joubert, D. From ultrasoft pseudopotentials to the projector augmented-wave method. Phys. Rev. B: Condens. Matter Mater. Phys. 1999, 59, 1758-1775.

(57) Adamo, C.; Barone, V. Toward reliable density functional methods without adjustable parameters: The PBE0 model. J. Chem. Phys. 1999, 110, 6158-6170.

(58) Paier, J.; Hirschl, R.; Marsman, M.; Kresse, G. The PerdewBurke-Ernzerhof exchange-correlation functional applied to the G21 test set using a plane-wave basis set. J. Chem. Phys. 2005, 122, 234102.

(59) Perdew, J. P.; Burke, K.; Ernzerhof, M. Generalized Gradient Approximation made imple. Phys. Rev. Lett. 1996, 77, 3865-3868.

(60) Scanlon, D. O.; Watson, G. W. On the possibility of p-type $\mathrm{SnO}_{2}$. J. Mater. Chem. 2012, 22, 25236-25245.

(61) Ganose, A. M.; Scanlon, D. O. Band gap and work function tailoring of $\mathrm{SnO}_{2}$ for improved transparent conducting ability in photovoltaics. J. Mater. Chem. C 2016, 4, 1467-1475.

(62) Vasheghani Farahani, S. K.; Veal, T. D.; Mudd, J. J.; Scanlon, D. O.; Watson, G. W.; Bierwagen, O.; White, M. E.; Speck, J. S.; McConville, C. F. Valence-band density of states and surface electron accumulation in epitaxial $\mathrm{SnO}_{2}$ films. Phys. Rev. B: Condens. Matter Mater. Phys. 2014, 90, 155413. 
(63) Lebens-Higgins, Z.; Scanlon, D.; Paik, H.; Sallis, S.; Nie, Y.; Uchida, M.; Quackenbush, N.; Wahila, M.; Sterbinsky, G.; Arena, D. A.; Woicik, J.; Schlom, D.; Piper, L. Direct Observation of Electrostatically Driven Band Gap Renormalization in a Degenerate Perovskite Transparent Conducting Oxide. Phys. Rev. Lett. 2016, 116, 027602.

(64) Sallis, S.; Scanlon, D. O.; Chae, S. C.; Quackenbush, N. F.; Fischer, D. A.; Woicik, J. C.; Guo, J.-H.; Cheong, S. W.; Piper, L. F. J. La-doped $\mathrm{SnO}_{2}$ - Degenerate perovskite transparent conducting oxide: Evidence from synchrotron x-ray spectroscopy. Appl. Phys. Lett. 2013, 103, 042105.

(65) Scanlon, D. O. Defect engineering of $\mathrm{BaSnO}_{3}$ for highperformance transparent conducting oxide applications. Phys. Rev. B: Condens. Matter Mater. Phys. 2013, 87, 161201.

(66) Ágoston, P.; Körber, C.; Klein, A.; Puska, M. J.; Nieminen, R. M.; Albe, K. Limits for n-type doping in $\mathrm{IIn}_{2} \mathrm{O}_{3}$ and $\mathrm{SnO}_{2}$ : A theoretical approach by first-principles calculations using hybridfunctional methodology. J. Appl. Phys. 2010, 108, 053511.

(67) Ágoston, P.; Albe, K.; Nieminen, R. M.; Puska, M. J. Intrinsic nType Behavior in Transparent Conducting Oxides: A Comparative Hybrid-Functional Study $\mathrm{In}_{2} \mathrm{O}_{3}, \mathrm{SnO}_{2}$ and $\mathrm{ZnO}$. Phys. Rev. Lett. 2009, 103, 245501.

(68) Graužinyte, M.; Goedecker, S.; Flores-Livas, J. A. Computational Screening of Useful Hole-Electron Dopants in $\mathrm{SnO}_{2}$. Chem. Mater. 2017, 29, 10095-10103.

(69) Powell, M. J.; Williamson, B. A. D.; Baek, S.-Y.; Manzi, J.; Potter, D. B.; Scanlon, D. O.; Carmalt, C. J. Phosphorus doped $\mathrm{SnO}_{2}$ thin films for transparent conducting oxide applications: synthesis, optoelectronic properties and computational models. Chemical Science 2018, 9, 7968-7980.

(70) Van de Walle, C. G.; Neugebauer, J. First-principles calculations for defects and impurities: Applications to III-nitrides. $J$. Appl. Phys. 2004, 95, 3851-3879.

(71) Lany, S.; Zunger, A. Assessment of correction methods for the band-gap problem and for finite-size effects in supercell defect calculations: Case studies for $\mathrm{ZnO}$ and GaAs. Phys. Rev. B: Condens. Matter Mater. Phys. 2008, 78, 235104.

(72) Hine, N. D. M.; Frensch, K.; Foulkes, W. M. C.; Finnis, M. W. Supercell size scaling of density functional theory formation energies of charged defects. Phys. Rev. B: Condens. Matter Mater. Phys. 2009, $79,024112$.

(73) Reuter, K.; Scheffler, M. Composition, structure, and stability $\mathrm{RuO}_{2}(110)$ as a function of oxygen pressure. Phys. Rev. B: Condens. Matter Mater. Phys. 2001, 65, 035406.

(74) Medeiros, P. V. C.; Stafström, S.; Björk, J. Effects of extrinsic and intrinsic perturbations on the electronic structure of graphene: Retaining an effective primitive cell band structure by band unfolding. Phys. Rev. B: Condens. Matter Mater. Phys. 2014, 89, 041407.

(75) Medeiros, P. V. C.; Tsirkin, S. S.; Stafström, S.; Björk, J. Unfolding spinor wave functions and expectation values of general operators: Introducing the unfolding-density operator. Phys. Rev. B: Condens. Matter Mater. Phys. 2015, 91, 041116.

(76) Williamson, B. A. D.; Buckeridge, J.; Chadwick, N. P.; Sathasivam, S.; Carmalt, C. J.; Parkin, I. P.; Scanlon, D. O. Dispelling the Myth of Passivated Codoping in $\mathrm{TiO}_{2}$. Chem. Mater. 2019, 31, 2577-2589.

(77) Button, K. J.; Fonstad, C. G.; Dreybrodt, W. Determination of the Electron Masses in Stannic Oxide by Submillimeter Cyclotron Resonance. Phys. Rev. B 1971, 4, 4539-4542.

(78) Thangaraju, B. Structural and electrical studies on highly conducting spray deposited fluorine and antimony doped $\mathrm{SnO}_{2}$ thin films from $\mathrm{SnCl}_{2}$ precursor. Thin Solid Films 2002, 402, 71-78.

(79) Jäger, S.; Szyszka, B.; Szczyrbowski, J.; Bräuer, G. Comparison of transparent conductive oxide thin films prepared by a.c. and d.c. reactive magnetron sputtering. Surf. Coat. Technol. 1998, 98, 13041314.

(80) Turgut, G.; Keskenler, E. F.; Aydın, S.; Sönmez, E.; Doğan, S.; Düzgün, B.; Ertuğrul, M. Effect of $\mathrm{Nb}$ doping on structural, electrical and optical properties of spray deposited $\mathrm{SnO}_{2}$ thin films. Superlattices Microstruct. 2013, 56, 107-116.

(81) Aydin, E.; De Bastiani, M.; Yang, X.; Sajjad, M.; Aljamaan, F.; Smirnov, Y.; Hedhili, M. N.; Liu, W.; Allen, T. G.; Xu, L.; Van Kerschaver, E.; Morales-Masis, M.; Schwingenschlogl, U.; De Wolf, S. Zr-Doped Indium Oxide (IZRO) Transparent Electrodes for Perovskite-Based Tandem Solar Cells. Adv. Funct. Mater. 2019, 29, 1901741.

(82) Nag, B. R. Electron Transport in Compound Semiconductors; Springer-Verlag, 1980; p 29.

(83) Rey, G.; Ternon, C.; Modreanu, M.; Mescot, X.; Consonni, V.; Bellet, D. Electron scattering mechanisms in fluorine-doped $\mathrm{SnO}_{2}$ thin films. J. Appl. Phys. 2013, 114, 183713.

(84) Pelliccione, C. J.; Timofeeva, E. V.; Segre, C. U. PotentialResolved In Situ X-ray Absorption Spectroscopy Study of Sn and $\mathrm{SnO}_{2}$ Nanomaterial Anodes for Lithium-Ion Batteries. J. Phys. Chem. C 2016, 120, 5331-5339. 